\title{
IMAGENS NO ESPELHO DE VÊNUS: MULHER, ENFERMAGEM E MODERNIDADE
}

\author{
Martha Cristina Nunes Moreira*
}

MOREIRA, M.C.N. Imagens no espelho de vênus: mulher, enfermagem e modernidade. Rev.latino-am.enfermagem, Ribeirão Preto, v. 7, n. 1, p. 55-65, janeiro 1999.

Objetivamos discutir o processo de construção da identidade profissional de enfermagem no marco da modernidade. Utilizamos como âncoras as categorias de gênero (Lobo, 1991) e pessoa moderna (Duarte, 1986). A modernidade como processo histórico situa a emergência do trabalho como categoria chave na relação público x privado. Entendendo a carreira como uma forma de construção e apresentação pública da pessoa moderna, discutimos o processo de construção da identidade profissional de enfermagem na relação com sua base feminina. Trabalhando a literatura etnográfica destes profissionais, vemos atualizado um imaginário que atribui à posição feminina da profissão grande parte de seus dilemas: crise de competência técnica, vocação e identidade.

UNITERMOS: enfermagem profissional, modernidade, gênero, pessoa, identidade profissional

\section{INTRODUÇÃO: nossa genealogia moderna e nossos compromissos}

A virada do século XVIII, sob os auspícios do ideário Iluminista, marca a constituição de um novo sujeito: aquele regido pela razão e pela vontade, senhor de um mundo desencantado e portanto, um mundo carente de ser conquistado pelos atributos individuais. A luz fornecida pela razão permitiria a decolagem para o pensamento científico através de uma dissecação do mundo, da realidade, para descoberta de leis e fenômenos. A verdade, agora lapidada pelo sujeito da razão, configura um domínio que tem na ciência seu fundamento legítimo. Dessa forma a razão, enquanto conjunto de conhecimentos, verdades e princípios, representava o passaporte necessário e suficiente para a instauração de um pensamento crítico sobre a realidade, visando transformá-la. Neste contexto ganhavam destaque os ideais de autonomia e vontade individual. A figura do contrato social se produz enquanto mediadora na relação do indivíduo com o Estado - e entre os próprios indivíduos - configurando a passagem de um estado de natureza para a condição de sujeito social. Em acordo com tal concepção individualista, a ação humana ganha potência ativa e tem na categoria de cidadão e na instituição dos direitos sociais de igualdade, liberdade e fraternidade, um marco fundamental.

A modernidade produz então, um processo contínuo de racionalização da vida, onde a liberdade e a igualdade configuram-se enquanto moedas simbólicas em um universo regido pelas leis do mercado e da ciência. A partir da leitura de Weber (1993) a modernidade caracterizar-se-ia a partir de uma tríade básica na qual concorreriam três processos constitutivos: um desencantamento do mundo, uma mundanização do sujeito e uma fraternização das relações. Nisto que agora marca a sociedade moderna, atualiza-se a urgência de instauração de um sujeito ativo e autônomo, independente da vontade divina. O deslocamento operado, tem na passagem de uma ética de denúncia da avareza - enquanto pecado e portanto fator de prejuízo ao indivíduo e a sociedade - para uma ética de valorização da ação individual, de acumulação terrena. $\mathrm{O}$ compromisso do sujeito com este mundo desconstrói o lugar de uma transcendência espiritual, na qual o sujeito possui uma capacidade mínima de interferência sobre seu destino. O mundo desencantado torna-se cenário para a criação individual, a partir do primado da razão no qual o sujeito torna-se imanente às obras que realiza. A sociedade baseada em um pacto entre iguais - estrutura do contrato social - enfatiza a construção de uma ética social no qual "o si para consigo" do desenvolvimento interior, torna-se inseparável do "si para com os outros" do intercâmbio social. Esta perspectiva da alteridade, essencial ao processo de individuação, serve a uma aproximação com o valor superior, englobante. Isto é, não mais encontramos a crença em um sujeito desvinculado dos bens terrenos como estratégia de salvação espiritual. Na realidade o

\footnotetext{
* Mestre em Saúde Pública ENSP/FIOCRUZ (1996), Psicóloga UERJ (1992), Departamento de Ensino/Instituto Fernandes Figueira/ FIOCRUZ
} 
sujeito moderno valoriza os bens que pode e deve desenvolver através do uso racional, a fim de tornar-se imagem e semelhança de um Deus autônomo ao qual importa a riqueza e a prosperidade de seus filhos. A uma divindade autonomizada corresponde um homem autonomizado, feito sua semelhança e imagem. Em acordo com esta recolocação do indivíduo perante o divino, Duarte (1993) afirma que: "A divindade não the vem de fora, ao Sujeito Moderno, ela lhe vem de dentro; e o olho da introspecção deve estar bem aberto, ritualmente aberto ao sentido maior que daí lhe pode e deve advir" (p. 41). Neste percurso urge a valorização de um processo de construção de si onde a razão estruture tanto um pacto social - remetido à dimensão relacional e do intercâmbio social - quanto promova a possibilidade de foco clareador sobre a interioridade subjetiva - desenvolvimento de um sentimento de responsabilidade, propiciando que a razão englobe a paixão e os sentimentos.

A valorização de uma análise e observação de si tem por fim a submissão dos sentimentos e emoções ao controle racional, na medida em que aqueles comportam uma dimensão de ilusão e prejuízo que deve ser afastada. Opõese a uma cultura dos sentimentos uma recusa e desconfiança do sensível através de uma empiricização da natureza, num processo de produção de conhecimentos que afastem os sentimentos enganadores. A ênfase dada a ação racional tem por vista a necessidade de corresponder a demanda de acumulação, para qual o controle emocional torna-se fundamento primordial.

A modernidade opera organizando antinomias: razão/ paixão, objetivo/subjetivo, privado/público. A internalização do sagrado institui o valor e o poder da ação individual no mundo, e a fraternidade torna-se fundamental em um pacto para o progresso científico e econômico-social, em um mundo onde reina o individualismo e a segmentação plural.

Duarte (1993) pontua no contexto da modernidade a instituição da cultura racional e seus possíveis efeitos sobre a produção dos sujeitos. Neste percurso moderno os valores de verdade, interioridade e vontade tornam-se máximas que perpassam as produções teóricas e discursivas do período. O indivíduo aparece enquanto resultado deste processo de construção da pessoa moderna, onde o "culto do eu" ganha lugar de destaque na representação de nossa cultura. Neste lugar de ser uno e indivisível, senhor da vontade e da verdade, a autonomia advinda do perfeito uso da razão possibilita ao indivíduo um vasto campo de papéis sociais. Neste universo fragmentado em contraposição ao mundo monacal e totalitário clássico, urge a mediação de instâncias institucionais com novos papéis: o Estado, a religião e a família. Uma leitura transversal dos três nos permite cartografar uma função comum: em um mundo onde reina a consciência individual e a liberdade, faz-se urgente a produção de uma identidade moral que não ultrapasse o limite da individualidade, e que possibilite um espaço de troca coletivizado com um mínimo de valores comuns.

\section{A CONSTRUCÃO DE IDENTIDADE DA PROFISSIONAL DE ENFERMAGEM: para além dos maniqueísmos, desvendando máscaras femininas}

Frente ao cenário descrito na sessão anterior, interessa-nos enfocar as transformações operadas quando da separação entre duas esferas da organização da vida social: a esfera pública e a esfera privada. A fim de ensaiar os possíveis efeitos produzidos sobre as relações de gênero no terreno do trabalho familiar e na entrada da mulher no mundo público pelo recorte profissional da Enfermagem. Interessa-nos portanto, pontuar algumas características que são trazidas pela literatura etnográfica, aqui entendida enquanto a produção de artigos realizada pela categoria de enfermagem sobre as sensações / percepções despertadas no exercício da profissão. A maioria destes artigos recorre à literatura sociológica sobre a organização social no contexto dos gêneros, relacionando-a à prática profissional de enfermagem. Utilizamo-nos da leitura destes artigos, relacionando os compromissos da modernidade, descritos anteriormente, com a leitura dos artigos produzidos pelas enfermeiras, buscando relativizar leituras maniqueístas acerca das posições de gênero. Tais posições maniqueístas, tendem a encobrir a complexidade que permeia as relações sociais e as produções dos sujeitos no cotidiano das práticas sociais. Por exemplo, o autoritarismo sempre referido nas relações entre médicos e enfermeiras no cotidiano hospitalar, tende por vezes a encobrir as relações autoritárias que são exercitadas entre os profissionais de enfermagem e os ocupacionais, no interior da equipe de enfermagem, ou até mesmo na relação cuidado de enfermagem / paciente.

Não raramente escutamos falas que referem-se às dificuldades suscitadas no encontro do mundo público - do trabalho - com a esfera privada - das relações domésticas e familiares. Inúmeras vezes o discurso da obrigatoriedade e necessidade de "deixar do lado de fora da porta do trabalho o mundo de problemas de casa" comparece ao cenário das relações entre sujeito e produção. Não raramente este discurso faz-se presente no cotidiano das mulheres que exercem a enfermagem, como se o primado da forma - profissional de enfermagem - se impusesse à possibilidade de expressão da vida, mulher-enfermeira.

Tal demanda de neutralidade e preservação do mundo público é socio-historicamente datada, e seletivamente apropriada pelos sujeitos no cotidiano das 
relações. Tal apropriação não se dá de maneira homogênea no caso das relações de gênero**. No contexto de racionalização do mundo, homens e mulheres sofrem os efeitos deste processo de forma desigual: tornam-se atributos masculinos as funções relativas a esfera pública, do trabalho e sustento, enquanto à mulher cabe a gerência do mundo da família, da esfera privada com a responsabilidade de cuidar das crianças e da reprodução da força de trabalho masculina. A desigualdade dos territórios fundamentou-se sobre supostas "naturezas biológicas e psíquicas" diferentes, operou-se uma masculinização da esfera pública concomitantemente ao estabelecimento de identidades a partir de papéis sociais pré-determinados. O discurso da ciência esteve presente, ditando normas e fundamentando teórica e conceitualmente tal desigualdade como demostrou Nunes (1991) a respeito da construção da medicina social sobre a questão feminina no Brasil (Nunes, 1991, p. 49-75).

A transformação da diferença entre homens e mulheres em um campo de desigualdades, aconteceu paralelamente à instituição de valores, normas, regras enfim, discursos e práticas conectados a atributos de ordem moral, hierarquizados de acordo com critérios de poder. Desta forma o trabalho na esfera doméstica, realizado pela mulher mãe e esposa, ganhou um colorido de inferioridade baseada em uma suposta natureza "frágil e menor" do feminino.

A dicotomização e o contraste entre as esferas pública e privada não se deu à parte de uma "sexualização das práticas". Segundo Lobo:”...as relações entre homens e mulheres são vividas e pensadas enquanto relações entre o que é definido como masculino e feminino - os gêneros. Neste sentido a divisão sexual do trabalho é um dos muitos locus das relações de gênero" (Lobo, 1991, p. 11).

Nesta linha a autora reflete acerca do trabalho como linguagem, utilizando-se do gênero como forma de falar da "subjetividade no trabalho", frisando que mentalidades e subjetividades formam-se e expressamse em cada esfera da existência, inclusive nas relações de trabalho.

A mulher na esfera pública, sua visibilidade através do mundo do trabalho fora de casa, não correspondeu as conquistas políticas. No Brasil em 1872 as mulheres representavam $45,5 \%$ da força de trabalho, no entanto somente no século XX, mais precisamente nos anos 20, a mulher conquista direitos civis de voto e educação (Pena, 1981). A questão da igualdade e das diferenças acabou por ser ocultada sob o manto da igualdade formal, tida como valor universal. Segundo Foucault (1991), o século das luzes inventou as nossas liberdades, mas garantiu um controle sutil através de um sólido e profundo suporte: a sociedade disciplinar da qual derivamos e que produzimos através de todo um sistema institucional, uma rede de práticas/saberes/subjetividades.

Os artigos de Gastaldo \& Meyer (1989), Lopes (1988) e Rezende (1993) buscam explorar os efeitos de uma história marcada pelas relações de gênero feminino sobre o cotidiano assistencial e organizativo da enfermagem.

Tratar de um tema como mulher e enfermagem, visando explorar uma história cercada de mitos e verdades datadas socio-historicamente torna-se desafio. Encontramo-nos frente a textos realizados por enfermeiras e que na maior parte utilizam-se da história através de um leitura determinista e fatalista: o poder do homem sobre a mulher, o lugar de vítima em que esta parece encontrar$\mathrm{se}$, a origem deste poder ligada ao patriarcado, o poder médico que submete a prática de enfermagem, entre outros temas.

$\mathrm{Na}$ literatura sobre gênero feminino e trabalho são fartas as referências à separação operada entre esfera pública e privada, durante o desenvolvimento da sociedade. A modernidade matizou tal separação com o colorido dos gêneros e algumas profissões ocupadas pela mulher produziram um terceiro universo de características híbridas. Isto é a saída de casa deu-se através de profissões tais como enfermagem e magistério, onde a mulher aparece com funções de cuidado e ensino remetidas ao universo familiar. É como se o hospital, para a enfermagem, ganhasse características de uma grande casa cuja demanda de gestão e organização recaísse sobre a enfermeira: misto de mãe e profissional.

Segundo Gastaldo \& Meyer (1989), em artigo no qual exploram a ênfase atribuída à conduta em detrimento do conhecimento na formação da enfermeira, a enfermagem constrói para si um imaginário no qual sobressaem dois aspectos: “...a enfermagem é uma profissão feminina por excelência, por ter sido sempre o cuidado à saúde uma atribuição da mulher. A enfermagem profissionalizada caracterizou-se, assim, como uma extensão do trabalho doméstico. O segundo aspecto diz respeito ao tipo de mulher que primeiramente prestou cuidados a doentes, como atividade remunerada: bêbadas, desqualificadas e prostitutas" (Gastaldo \& Meyer, 1989,

\footnotetext{
** Tal conceito é utilizado em acordo com a definição proposta por Elizabeth Souza Lobo:"conjunto de representações sociais construídas a partir das condições biológicas das diferenças entre os sexos" (Lobo, 1987, 93). É uma categoria sociológica chave, que possibilita instrumentar uma perspectiva relacional e performática quando se pensa a construção social das diferenças entre os sexos
} 
p. 7). A genealogia da enfermagem resgata uma "préhistória" que raramente comparece na formação de novos enfermeiros, o aspecto técnico-científico do cuidado de enfermagem tende a ser inflacionado, como retrato do primado da forma, daquilo que "deve ser" o padrão da enfermagem moderna.

A ponte construída entre o cuidado realizado de forma artesanal nos "hospitais hospedarias", e o hospital moderno é bem retratado por Foucault (1979). O cuidado aos doentes de início era realizado nos hospitais de forma filantrópica e caritativa, sob a responsabilidade das irmãs de caridade. Um hospital ainda não medicalizado, lugar para morrer e não para curar, como nos diz Foucault (1979, p. 99). O século XVIII marca a entrada do médico e a submissão do cuidado à cura, das freiras ao médico, no entanto tal relação gradativamente vai se transformando e o cuidado passará a ser exercido de forma remunerada por um pessoal não qualificado: as prostitutas, bêbadas, mulheres de reputação duvidosa, agora o inverso da pureza religiosa. A enfermagem profissional nasce no século XIX com o interesse de Florence Nightingale - dama da alta sociedade inglesa pela "arte de cuidar". Urge resgatar a imagem dos hospitais e assim superar a resistência das famílias a autorizar suas filhas a cuidar de doentes. A necessidade de vinculação da imagem do cuidado à devoção, à arte assexuada de dedicar-se ao próximo estrutura o cenário.

Assim o ato de cuidar naquele momento, remetia a determinados pré-requisitos: idoneidade moral, devoção, desprendimento, submissão e capacidade de gestão do espaço hospitalar tal como uma "casa". Tais requisitos informavam uma reação a uma história anterior que conectava tal prática de cuidado a uma imagem de mulher negativa para os padrões morais. Resgatar uma suposta natureza feminina pura, tornava-se urgente a fim de garantir um espaço profissional e a saída desta mulher de casa. Esta saída só podia se dar em acordo com o imaginário fundante da esfera privada/familiar, pautada em uma suposta vocação feminina para nutrir, cuidar e gerir.

A modernidade marcada pelo paradigma positivista, instituiu valores que passaram a referir a utilidade e a finalidade das ações, neste contexto eficiência e eficácia configuraram-se instrumentos que transversalizam diversas ações em diversos campos de conhecimento. $\mathrm{O}$ controle baseia a ação profissional no mundo, um mundo cuja perspectiva moral se coaduna a produtivista pasteurizando as formas de percepção e atuação no universo das regras, costumes e instituições.

Segundo Rezende (1993) faz-se necessário neste contexto - do qual a instituição da enfermagem profissional faz parte - produzir análises que expliquem, controlem e transformem a imagem da enfermagem a partir de um jogo de opostos. Tais antinomias fabricam, segundo a autora, armadilhas que mais desejam domesticar as diferenças, ao reduzir a complexidade da totalidade a fragmentos a fim de dividir para conhecer e controlar, submetendo a vida à forma: “...era preciso opor à enfermeira-anjo à técnica, empenhada (ou perdida) em pequenas tarefas detalhistas na busca de eficiência. Ao símbolo sexual, a enfermeira assexuada, rígida, séria, substituindo, na aridez da hiper-honestidade artificial, toda a alegria de viver. À ajudante do médico, a administradora, com status e papel definido na técnico-burocracia e, sobretudo, concorrendo com aquele em competência" (Rezende, 1993, p. 29).

A autora refere a artificialidade das análises organicistas como responsáveis pela redução da complexidade dos fenômenos - fluidos, mutáveis, inconstantes, e no caso da prática de enfermagem referida à emoção, à representações sociais e imaginárias produtoras de realidades e mitos - à relações de causaefeito. Tais relações tem por base um imperativo do "dever-ser", a norma e a moral social de caráter explicativo com vistas a fabricar uma nova realidade. A linearidade desta visão racional e positivista que impregna olhar do homem sobre o mundo, segundo Rezende (1993), conseguiu determinar invariâncias mas a produção de diferenças e invariâncias constitui a relação do homem com o mundo, sua prática e seu saber.

Tal processo produz e é produzido pelos sujeitos, em um cotidiano múltiplo: cotidiano das relações de gênero, das relações de produção familiares, educacionais e profissionais. A multiplicidade de sentidos produzidos no universo atual, tende a passar por canais semióticos que buscam reduzir e formatar as diferenças. Neste caso a mídia, as instituições que nos constituem sujeitos ocupam um papel vital. Se a esfera privada das relações familiares - nucleares, intimistas que a modernidade inaugura participa em um primeiro momento fornecendo a base de valores e significações socializantes, a esfera pública da educação, do trabalho e das relações afetivas extensas produzirá uma ampliação do universo societal. Tal ampliação possui na base anterior fundamentos dos quais parte, de forma tal que esta rede institucional produz um tecido de relações que convergem, divergem e multiplicam.

Falamos deste percurso de socialização como forma de introduzir a questão do processo de produção da pessoa moderna na relação com o trabalho. No caso do presente ensaio as implicações de uma profissão marcada pelas relações de gênero feminino, instituída no contexto moderno, fornece um colorido acerca da necessidade de estabelecimento de uma separação entre o mundo público e o privado. Já foi possível perceber a operação de uma sexualização das práticas quando da entrada da mulher no mundo público através do trabalho extra-doméstico. 
A instituição da enfermagem profissional deu-se através da necessidade de sua afirmação enquanto prática "moralmente idônea". Para tanto recorreu aos estereótipos que remetiam e reforçavam a existência de uma natureza feminina da qual faziam parte atributos de submissão, caridade, abnegação e paciência. No entanto a potencialidade feminina para curar, realizar partos e cuidar de enfermos presentificava-se na idade média como atributo das parteiras e bruxas. Tais atributos, essencialmente femininos, gradativamente passaram a ser negativados e percebidos enquanto astúcia maligna pela religião e as mulheres que desenvolviam esta potencialidade foram percebidas enquanto bruxas e portanto queimadas e renegadas. Assim segundo Ehrenreich \& English (1973), em um importante estudo sobre o parentesco existente entre as bruxas, parteiras e enfermeiras, as "mulheres que curam": “...bruxas foram perseguidas por serem objetivas, por possuírem um saber empírico e imoral. Mas no século XIX a retórica reverteuse: mulheres tornaram-se também impossibilitadas de desenvolver um saber científico, por serem delicadas e sentimentais. Os estereótipos mudaram para seguir a conveniência masculina - não existe nada em nossa "natureza feminina inata" para justificar nossa subserviência atual." (Ehrenreich \& English, 1973, p. 42).

Ainda segundo as autoras, a enfermagem é simplesmente uma ocupação que representa uma extensão dos papéis de esposa e mãe, vividos no interior do universo doméstico, no contexto do sistema de saúde.

Desta forma podemos observar um contraste de imagens na história da enfermagem. Uma profissão voltada para a arte de cuidar, envolta em uma aura de emoções e imagens corporeificadas em mitos e estereótipos que jogam em um cenário colorido por maniqueísmos.

A enfermagem parece operar uma aproximação entre o mundo público e o mundo doméstico, através de um trabalho identificado como feminino. As tarefas de cuidado, higiene, gestão do espaço hospitalar aproximamse do universo doméstico e não raramente as enfermeiras(os) referem um sentimento de "donos-decasa".

É interessante observar que a partir de uma análise acerca do caráter feminino da profissão - no qual poderiam sobressair os aspectos positivos do feminino, tais como a leveza, o encantamento - o que vem reativamente à superfície é o predomínio e o valor atribuído à atividades finalistas, rígidas, assépticas e enérgicas. A entrada da mulher no mundo do trabalho parece ocorrer às custas da perda de sua singularidade: é o processo de masculinização da mulher como estratégia de afirmação. Tal perspectiva parece reafirmar o quanto é poderosa a representação do mundo do trabalho como masculino e a valorização destes atributos como os melhores.

Neste cenário debatem-se identidades em um jogo de antagonismos e antinomias. Os pólos feminino e masculino congelam imagens de forte/fraco, emocional/ racional, inferior/superior. As diferenças que caracterizariam possibilidades de relações de complementaridade e deveres não remetidos à territórios sedentários, acabam por ganhar identidades baseadas em critérios de desigualdade. Segundo Guattari \& ROLNIK (1986): “...identidade e singularidade são duas coisas completamente diferentes. A singularidade é um conceito existencial; já a identidade é um conceito de referenciação, de circunscrição da realidade a quadros de referência, quadros esses que podem ser imaginários...em outras palavras, a identidade é aquilo que faz passar a singularidade de diferentes maneiras de existir por um só e mesmo quadro de referência identificável" (Guattari \& Rolnik, 1986, p. 68).

Neste contexto a identidade congela as maneiras de olhar femininas e masculinas à perspectiva dos sexos, restringindo à naturezas biológicas diversas um determinismo de papéis e funções a-históricas. Tal funcionamento tem sua eficácia e perpetuação através dos discursos e práticas dos sujeitos sociais, na forma de uma enunciação coletiva*** que não limita-se a classes sociais e nem obedece a modelos econômicos ou ideológicos, de alienação ou conscientização. Neste sentido todos encontram-se envolvidos nesta rede disciplinar autônoma, anônima, dispersa e programática. Tal modelo permite deslocarmo-nos de uma história referida a opressores e oprimidos, vítimas e algozes, muito embora certos saberes, regras e normas funcionem como hegemônicos e portanto como referências a partir dos quais se estruturam certas práticas.

No caso das profissões, Bourdieu refere-se às mesmas enquanto uma construção social: “...produto de todo um trabalho social de construção de um grupo e de uma representação dos grupos, que se iniciou docemente no mundo social" (Bourdieu, 1989, p. 40). Entendendo as profissões enquanto construções sociais, podemos

\footnotetext{
*** Tal expressão conecta-se intimamente com a noção de produção de subjetividade. Isto é, a subjetividade deixa de ser encarada como coisa em si, essência imutável e passa a ser produzida através dos agenciamentos coletivos de enunciação espraiados no tecido social através dos discursos, práticas, instituições, mídia. Desta forma os agenciamentos coletivos de enunciação produzem identidades mas não se reduzem a estas, implicando a entrada de diversas coleções de objetos técnicos, de fluxos materiais e energéticos, de entidades incorporais, estéticas, etc. (Guattari \& Rolnik, 1986).
} 
relacionar a enfermagem profissional, seu surgimento no marco da modernidade e seus valores e atributos femininos, ao campo das relações sociais, expectativas e pré-conceitos que articulam as demandas por especializações profissionais à determinadas visões culturais acerca destas práticas e daqueles que a exercem como grupo organizado.

Neste campo de significados construídos e compartilhados, os conceitos de habitus e campo desenvolvidos por este mesmo autor, apresentam-se enquanto extremamente operativos na medida em que encontram-se em referência a todo um aparato que associa poder e simbolismo. O conceito de habitus ganha matizes de uma capacidade criadora, inventiva, ativa sendo ao mesmo tempo adquirido e passível de tornar-se capital, um "haver" que situa um agente em ação. Neste território o conceito de campo propicia o trabalho com um determinado universo no qual existem agentes em relação, e onde a autonomia configura-se sempre como relativa.

A enfermagem caracteriza-se por um componente essencialmente feminino e no cenário hospitalar encontra-se articulada à profissão médica, debatendo-se nas redes da submissão e da cultura hospitalar. A literatura etnográfica da categoria bem como o discurso produzido acerca de sua prática, parece afirmar uma cultura profissional na qual dois dilemas encontramse articulados: um imaginário mimético com relação à medicina e um imaginário feminino de submissão e inferioridade. A possibilidade de reflexão acerca dos dilemas desta categoria pode vir a ser buscada no enfrentamento do imaginário que investe e produz determinados significados atualizados enquanto saberes e práticas no cotidiano hospitalar.

\section{A TÍTULO DE ABERTURA: da unidade à pluralidade}

Cruzando as categorias empíricas - vocação e competência técnica - com o referencial teóricometodológico que baseou este trabalho, baseado na leitura de artigos escritos por profissionais de enfermagem, pudemos perceber que estas duas categorias conformavam a operação de construção da categoria analítica identidade profissional.

A identidade dos profissionais de enfermagem parece construir-se através de um processo complexo de relações de alteridade, onde as aproximações e afastamentos para com a profissão médica e as ocupações de enfermagem referem distinções e diferenças, que tendem a ser englobadas por hierarquizações simplificadoras.
Uma destas hierarquizações pode ser referida ao lugar privilegiado nos discursos à relação de subordinação do enfermeiro ao médico. No entanto o que percebemos é a necessidade de deslocar-se desta primeira aproximação, a fim de alcançar a singularidade da profissão de enfermagem moderna, que instituiu um trabalho em equipe - onde estas subordinações e disputas de poder também têm lugar, principalmente quando se distingue a gerência da assistência, e se classifica a primeira como distanciamento do cuidado, menosprezo da prática. É como se víssemos atualizadas as discussões acerca da teoria versus prática, onde o enfermeiro é percebido/se percebe, e ao mesmo tempo nega, o risco de burocratizar-se, distanciando-se daquilo que seria a "essência" da profissão: o cuidado.

A aproximação para com o campo de saber médico é muitas das vezes valorizado nos discursos como estratégia de conquista de reconhecimento social e profissional. É preciso aproximar-se da medicina e diferenciar-se dos ocupacionais de enfermagem, neste processo identifica-se claramente aquilo de que os profissionais de enfermagem queixam-se na relação com os profissionais médicos: hierarquia fortemente demarcada pelo uso da autoridade ancorada na supervisão e gerência das ações.

Ao cuidado assistencial é atribuído um valor maior, reforçando esta via como o ato fundador da profissão, recorrem à história como que justificando um retorno a estas origens: o cuidado direto ao paciente, sem as divisões de trabalho, sem a fragmentação da equipe. Neste sentido a leitura que fazem da história pregressa da enfermagem - a enfermagem tradicional - é reativamente buscada a partir de um olhar continuísta que parece não identificar os atos fundadores da profissão, comprometida com a racionalização das ações e os rituais de seleção que visaram garantir reconhecimento social e no campo profissional - conquistando candidatos de origem "nobre".

Um discurso já conhecido no interior desta categoria e também exterior a ela tenta afirmar problemas no que concerne ao tema vocação/opção pela profissão: tal opção seria, na maioria dos casos, sempre secundária e hierarquicamente inferior à profissão médica. Tal dinâmica parece produzir uma cultura na qual dois dilemas encontram-se articulados: um imaginário mimético com relação à medicina e um imaginário feminino de submissão e inferioridade. Esta produção cultural da enfermagem parece pontuar na atualidade uma aproximação cada vez mais acentuada destes profissionais com o equipamento teórico, técnico e discursivo da medicina, apesar de possuírem um saber e uma prática diferenciada do objeto e prática médicas.

A permanência de um discurso religioso na prática de enfermagem atualiza-se na categoria vocação, que retoma os ideais de missão divina, de internalização do sagrado. 
Pela própria singularidade de seu processo teórico-técnico, a enfermagem funda o trabalho em equipe como um dos pilares de sua existência. A associação entre o surgimento da enfermagem como profissão na modernidade e o ideário histórico e cultural do período permitiu-nos rever os compromissos da profissão com a racionalização das ações, a intelectualização e conseqüente desencantamento do mundo.

$\mathrm{Na}$ realidade poucos foram os profissionais que perceberam o aspecto educativo da prática, que se estabelece tanto na relação com os ocupacionais - quando supervisionam e capacitam - quanto na relação com os pacientes, tendo em vista o auto-cuidado e a autonomia destes. Os profissionais entrevistados que exerciam funções no contexto hospitalar e também eram docentes, atingiam com maior clareza este aspecto, valorizando-o com aquilo que os singularizava como profissionais da saúde.

As ocupações de enfermagem, instituídas a partir da organização do processo de trabalho da enfermagem moderna, acabaram por tornar-se, pelas distorções do sistema hospitalar brasileiro, uma parcela significativa das ações de cuidado ao paciente. Desenvolvendo um saber técnico e auxiliar, muitas das vezes acumulado na empiria da assistência, estes trabalhadores acabaram por inverter o tradicional eixo valorizado academicamente: acumulam saber e conhecimentos práticos e terminam atuando pela proximidade com os profissionais de enfermagem, como "instrutores informais". Tal análise de alguma forma é ratificada pelos discursos analisados, que referem-se a estes trabalhadores como um dos pólos de identificação. Mas um pólo que hierarquicamente coloca-se em uma posição subordinada, de complementaridade, e do qual é necessário afastar-se, exercendo liderança.

O tema da competência técnica revelou conflitos que poucas vezes são nomeados no interior da própria cultura de enfermagem. A tendência a encarar a oposição enfermagem versus medicina, privilegiando-a enquanto espaço de disputa de poder, restringe a complexidade de relações que estruturam-se no interior da própria equipe de enfermagem e que presentificam conflitos estruturais no território de demarcação de competências. Assim discursos nomeiam a dificuldade de tornar clara na prática a divisão técnica do trabalho e a diferença entre um ocupacional e um profissional de enfermagem. Além do mais o número de ocupacionais na assistência hospitalar é visivelmente superior, o que provoca nos hospitaisescola uma transmissão de conhecimento que inverte, por vezes, o eixo tradicionalmente reconhecido no campo da formação profissional: os estudantes aprendem com a experiência e saber acumulado, em parte, empiricamente pelos ocupacionais.

A medicina, com seu saber e prática, encontra- se no outro pólo da relação de alteridade que o profissional de enfermagem desenvolve no processo de construção de referências identitárias. A hegemonia do médico, o esoterismo de sua prática, seu alcance e reconhecimento social colocam-no como um "modelo"/ "espelho" do qual é sedutor aproximar-se.

Estes dois pólos, um ocupado pelos ocupacionais e outro pelos enfermeiros, parece instaurar um coeficiente conflituoso que por vezes tende a ser reduzido e referido apenas à relação médico / enfermeiro, tornando-se locus de discursos ressentidos e queixosos.

Os profissionais de enfermagem parecem não perceber no conflito um motor de sua história e de sua prática, apesar deste ser a todo momento enunciado. Quando retomamos na tradição moderna a análise das operações vividas pela sociedade no alvorecer iluminista, percebemos que esta análise identifica pares antinômicos sintetizados na relação ser versus fazer. Os autores que tematizaram as transformações introduzidas pela agenda da modernidade identificavam a necessidade de revitalizar o conflito como motor de construção dos grupos e dos processos. Era preciso contrapor ao sangue e a herança - este pólo que tematiza o ser - o poder do trabalho, da construção de si através da carreira, enquanto grupo e cultura técnica - o pólo fazer. Tendo em vista o nascimento da enfermagem moderna pautada em compromissos técnico-científicos, de ruptura com uma história anterior "profana" e leiga, o ideário histórico e cultural do período moderno vai ao encontro do que Weber (1993) caracteriza como sendo os pilares da modernidade: a racionalização das ações, intelectualização, fraternização e desencantamento do mundo.

O habitus escolar (Bourdieu, 1989) dos profissionais de enfermagem atualiza portanto certas matrizes que reforçam as hierarquias, os valores morais e estereótipos que parecem buscar uma certa invariância: tema que alcança o território da identidade como continuidade.

No entanto é importante considerar que a todo momento, quando buscávamos caracterizar a enfermagem tradicional e a moderna, situando o esforço desta última de delimitar rupturas para com os praticantes anteriores leigos, buscando a instituição formal em contraposição ao empiricismo, tínhamos por objetivo introduzir o leitor em um outro campo de possibilidades: o campo em que concorrem lutas e esforços de reconhecimento totalmente referidos ao contexto histórico-social concreto. Daí trabalhar com o conceito de profissão relacionando-o ao território em que determinadas demandas são formuladas socialmente e contribuem para a intervenção dos especialistas, e suas competências formais.

É interessante deixar registrado que quando iniciamos este percurso não objetivamos explorar as questões referentes à origem racial no campo da 
enfermagem profissional, apesar de ser facilmente perceptível o elevado contigente de negros na profissão. $\mathrm{Na}$ pesquisa à literatura etnográfica este tema não fezse presente, sendo por vezes tangenciado quando era referida a relação com os ocupacionais e o esforço destes em alcançar o status de profissionais.

A enfermagem, como o magistério, caracterizase como uma profissão de mulheres, profissão, que no mundo público, representava uma extensão do lar, das representações de um feminino dócil, que cuida, nutre e educa.

Quando buscamos escapar às leituras que interpretam às crises da enfermagem seja a partir do referencial estruturalista marxista, seja da sociologia das profissões, pretendemos deslocar-nos das leituras macro, que contribuem como leitura e aproximação, mas que não conseguem explorar as nuances dos mecanismos de exclusão, inclusão, seleção, que não deixam de enviarnos ao território histórico-social concreto, no cruzamento entre estrutura e conjuntura.

Daí considerarmos, depois deste percurso em que o leitor pôde nos acompanhar, que além das relações profanas e sagradas que referem o feminino da profissão, podemos pontuar, também, o lugar ocupado pelo imaginário mimético com relação ao campo médico e além desses dois nichos introduzimos a questão da interface com o campo do magistério e da esfera de distinção pela raça, critérios de seletividade no início da profissão no Brasil.

Reconhecemos que hegemonicamente as análises críticas optam pelo esquema explicativo dos estereótipos de gênero, no entanto acreditamos que a construção de uma identidade profissional fala-nos de um território multivariado, que foi nomeado nos discursos durante os momentos de observação participante. Percebemos que o valor atribuído ao feminino é tão forte, que o contigente masculino na profissão sofre com os olhares indagadores acerca de sua condição erótica.

Achamos interessante também perceber que os profissionais de enfermagem dialogam não só com os médicos, mas principalmente com o campo médico (Coradini, 1988) que fala das lutas por afirmação de um determinado exercício de prática que transcende a própria medicina como campo de produção científica. E informa acerca da força das representações que associam um valor maior a esta ou aquela prática profissional. Esta linha de pensamento leva-nos a refletir acerca da constituição da equipe de enfermagem, pautada na heterogeneidade e nos reflexos vividos na relação com o campo médico, referido acima. Esta heterogeneidade parece revelar conflitos que encontram-se estruturando as práticas e funcionando como elemento de coesão, ao contrário de configurar-se enquanto ponto negativo, ela parece afirmar e estruturar o campo de atuação dos profissionais na relação com os ocupacionais de enfermagem em um cotidiano de supervisão, gerência e administração do cuidado ao paciente.

A percepção de fragilidade de competência técnica dos profissionais de enfermagem vinha correlacionada à heterogeneidade da equipe e a sensação de que o seu campo de atuação apresentava uma dispersão. Isto é, era necessário gerir a assistência, coordenar uma equipe, capacitá-la, realizar quando necessário procedimentos mais complexos e por distorção da estrutura hospitalar, tornavam-se "donos-de-casa" que providenciam consertos e materiais. Os conflitos surgidos neste campo acentuam-se quando denunciam o não reconhecimento e desrespeito das instituições acerca das habilitações e especialidades desenvolvidas. Neste momento o reconhecimento social do campo médico comparece ao cenário, como paradigma e motor de discursos ressentidos.

A categoria vocação nos enviou à força da matriz feminina da enfermagem e a seus dilemas. Abrindo-se em dois planos: um das representações profanas do feminino que necessitavam ser superadas a fim de afirmar o segundo plano, sagrado, de um feminino congelado aos estereótipos de gênero que produziram na prática dos profissionais de enfermagem um efeito de extensão do mundo privado para o público. Waldow (1995) em artigo que busca rever a formação da enfermeira a partir da perspectiva de gênero, cita Nightingale para quem a boa enfermeira caracteriza-se por ser: “...uma pessoa com quem se pode contar, uma mulher de sentimentos delicados e recatados, observadora sagaz e discreta, sóbria e honesta, religiosa e devotada, enfim, alguém que respeita sua própria vocação, porque a vida, a mais preciosa dádiva de Deus, é posta em suas mãos" (Meyer apud Waldow et al., 1995, p. 63).

Acerca do nicho feminino, percebemos a pregnância e o valor atribuído pelos profissionais majoritariamente mulheres - na análise das relações que o conformam. Feitas analistas de sua própria profissão, as enfermeiras valorizam as leituras que abordam os estereótipos de gênero e a história dos valores e modelos intervenientes nas teorias que conformaram seu campo profissional. A relação com as forças sociais, os estereótipos e interesses atualizam-se neste percurso transfigurando os significados de uma profissão que nasceu sob a égide do feminino. As profissionais de enfermagem atualizam em suas práticas e discursos uma polissemia de significados, construídos socialmente ao redor de uma suposta natureza feminina que oscila entre as representações profanas e sagradas deste universo.

A categoria vocação aparece também no discurso dos profissionais remetida a uma visão essencialista, de chamamento para a carreira. Tal análise vai ao encontro das representações acerca do nicho 
feminino, das relações de gênero, dos rituais de seleção dos quais a questão racial também faz parte.

Quando consideramos que as duas categorias empíricas cruzam-se e produzem interfaces, queremos dizer que a questão da competência técnica estaria mais remetida ao imaginário mimético com relação à medicina - a "costelinha" a qual uma de nossas entrevistadas fez referência, e que falam de parentescos simbólicos de complementaridade e submissão - na medida em que o profissional de enfermagem em seu cotidiano lida com dois segmentos: o dos médicos e o dos ocupacionais. E a categoria vocação pareceu-nos afirmar o lugar dos parentescos sagrados e profanos do feminino, e dos rituais de seleção e exclusão dos "puros e impuros".

A categoria competência técnica enviou-nos aos dilemas surgidos do encontro com a medicina, e com a heterogeneidade que caracteriza a equipe de enfermagem. Ao esoterismo da medicina e incomunicabilidade / invisibilidade das ações foi contraposta uma formação que se funda em uma complexidade de ações que produzem uma sensação de pulverização no campo de saber. Isto que pudemos identificar, levou-nos à competência difusa destes profissionais, exercício de socialização do conhecimento, auto-avaliação constante e capacitação da equipe.

No entanto, este aspecto que funda uma relação estreita entre educação e saúde, não consegue afirmarse aos olhos dos profissionais de enfermagem que atuam no hospital. É assim que os cuidados profissionais realizados nas unidades de terapia intensiva passam a ser mais valorizados na carreira, em função disto que funda o impulso à especialização, entendida como um fortalecimento da competência, acúmulo de conhecimento, com correlativo reconhecimento no mercado de trabalho.

Este trabalho não pretende conclusões definitivas mas visou estudar os meandros constitutivos de uma cultura profissional. Tornou-se instigante trabalhar com os profissionais de enfermagem enquanto um grupo, produtor de uma determinada cultura técnica, no campo heterogêneo das profissões. Explorar representações, dilemas, nichos conflituosos significa valorizar a potência dos discursos e multiplicar possibilidades. O tema identidade profissional é por si só complexo, até porque tivemos por preocupação escapar dos reducionismos da unidade que por vezes tal tema tangencia. Provisoriamente mais do que uma unidade de representações produtora de uma identidade profissional, fomos apresentados a uma pluralidade de sentidos que reativam a história e a heterogeneidade.

O tema fundamental do pensamento iluminista é o da oposição entre "público" e "privado", no que concerne a emergência do sujeito político na relação com o Estado. A preservação da liberdade individual se dá na esfera da família nuclear, a construção da intimidade necessária à natureza humana e fundamental para basear a saída para o mundo público.

A processo de saída da mulher para a esfera pública, do trabalho extra-doméstico, deu-se através de profissões que barravam a ruptura com o universo privado. A mulher saía de casa para trabalhar mas permanecia atrelada a suposta natureza de submissão e docilidade, a tarefas de cuidado, ensino, costura, etc.

A nós interessou mapear, de uma forma ao mesmo tempo panorâmica e específica, a instituição da mulher no mundo público, pelo recorte do trabalho em enfermagem. Uma profissão que se faz analisador**** de uma série de estereótipos referidos ao gênero feminino e que portanto traz à visibilidade :"...a articulação da vida privada com a vida pública, no papel internalizado da prioridade à reprodução e ao mundo doméstico" (Lopes, 1988, p. 213)

Este congelamento a uma suposta identidade e equivalência da mulher à mãe e esposa, obscurece outras dimensões da mulher enquanto profissional e cidadã. Torna-se desafio a construção da igualdade na diferença e a passagem da domesticidade à cidadania.

A modernidade inaugura o indivíduo, ser uno e indivisível e sua imagem vem a ser distinguida de acordo com uma ordem identitária que lhe confere um lugar social reconhecido. Frente a uma ordem urgente de ser superada o trabalho institui-se enquanto passaporte necessário para a caminhada e ascendência social. $O$ trabalho feito moeda simbólica transforma as relações sociais anteriormente baseadas nos laços de sangue. À aristocracia de sangue contrasta-se a aristocracia de espírito, representada pela classe burguesa tutora da nova ordem. Este "caldo" cultural, econômico e social que o século XVIII inaugura produz novos valores, transforma e ressignifica instituições - família, trabalho, espaço público, espaço privado - e torna urgente a identificação dos indivíduos em seus novos papéis e funções.

É assim que uma leitura transversal destes acontecimentos - transversal por permitir e desejar superar um puro nível vertical das relações de determinação das leituras economicistas ou um simples nível horizontal de relações de dominação - busca construir um olhar histórico-crítico acerca de diversas transformações e efeitos operados pelo saber/discurso/prática iluminista sobre a constituição da pessoa moderna com seus ideais de verdade, interioridade e vontade.

**** Analisador, no vocabulário da análise institucional, pode ser entendido enquanto um acontecimento, indivíduo, prática ou dispositivo que permite trazer à superfície o impensado de uma estrutura social 
A nós interessou mapear dois campos: primeiro a instituição pela modernidade de uma imagem que masculiniza o espaço público do trabalho, e identifica a imagem do homem ao equivalente do poder de transformação, do controle emocional das ações e do projeto intelectual, relegando a mulher ao mundo doméstico da gestão de casa/marido/filhos; segundo com a reorganização do espaço hospitalar e a apropriação por parte da medicina da direção deste espaço, medicalizandoo e inaugurando a profissão médica e sua hegemonia atual ${ }^{* * * * *}$, houve toda uma referência a este saber e de uma certa forma à identidade médica de forma especular e subserviente por parte da enfermagem, produzindo o que poderíamos denominar uma "identidade paramédica". Neste nicho imaginário cruzam-se determinadas representações produzidas acerca do gênero feminino com a "permissão" do trabalho de enfermagem no campo hospitalar, referido à cura e tendo o cuidado como função acessória.
Talvez a abertura para outras possibilidades de enunciação de histórias acerca da enfermagem na atualidade, advenha do reconhecimento de uma história povoada por bruxas, parteiras, anjos e lâmpadas, não para localizar origens mas para traçar uma arqueologia. Entendendo cultura enquanto um conceito semiótico, Geertz (1978) nos fornece pistas importantes para o trabalho com significados subjacentes às práticas. $\mathrm{O}$ autor define cultura enquanto um conjunto de mecanismos de controle - planos, receitas, regras e instruções - para governar o comportamento, situando o homem como dependente de tais mecanismos e ao mesmo tempo como ser "não-natural" e nem muito menos universal. Instrumentalizar tal conceito e associá-lo ao tema da profissionalização e da socialização da categoria de enfermagem pode vir a significar uma abertura deste campo para uma rede de saberes, práticas, discursos e subjetividades referidos ao âmbito de uma produção coletiva.

\section{IMAGES IN THE VENUS’ MIRROR: WOMAN, NURSING AND MODERNITY}

This paper discusses the process of nursing professional identity construction in modernity. We utilize the ideas of category gender (Lobo, 1991) and modern person (Duarte, 1986). The modernity as a historical process establishes the emergence of work as a central category in the public X private relationship. Understanding the profession as form of construction and public presentation of the modern person, we discuss the nursing professional identity process in relation to its female basis. Working on nursing ethnographic bibliography, we identify a picture that gives to the female basis of the profession the greater cause of dilemmas such as: technical competence, vocation and identity.

KEY WORDS: professional identity of nursing, modernity, gender, person

\section{IMÁGENES EN EL ESPEJO DE VENUS: MUJER, ENFERMERÍA Y MODERNIDAD}

El objetivo de esta investigación fue discutir el proceso de identidad de enfermería en el marco de la modernidad. Usamos como puntos de apoyo las categorías de género (LOBO, 1991) y de persona moderna (DUARTE, 1986). La modernidad como proceso histórico situa el surgimiento del trabajo como categoria clave en la relación entre lo público y lo privado. Entendiendo la carrera como un proceso de construcción y presentación pública de la persona moderna; discutimos el proceso de construcción de la identidad profesional de enfermería en relación con su base femenina. Trabajando la literatura etnográfica de estos profesionales, vemos actualizado un imaginario que atribuye a la posición femenina de la profesión grán parte de sus dilemas: crisis de competencia técnica, vocación e identidad.

TÉRMINOS CLAVES: enfermería profesional, modernidad, género, identidad profesional

\section{REFERÊNCIAS BIBLIOGRÁFICAS}

01. BOURDIEU, P. O poder simbólico. Lisboa, Difel, 1989.

\section{CORADINI, O.L. Representações sociais e conflitos} nas políticas de saúde e previdência social rural. Rio de Janeiro, 1988. Tese (Doutorado) Programa de Pós-graduação em Antropologia Social/Museu Nacional/Universidade Federal do Rio de Janeiro.

***** A prática médica é milenar no entanto a profissão médica tem seus fundamentos no século XVIII, idade das luzes e fundamentalmente passa a ocupar um lugar de aliança com o Estado no tocante à organização não somente dos hospitais, mas também do espaço urbano e familiar - através do dispositivo higiênico. Para melhor exploração do tema de forma breve e sintética vide FOUCAULT, M. Microfísica do Poder. RJ, Graal, 1979 
03. DUARTE, L.F.D. Da vida nervosa nas classes trabalhadoras urbanas. Rio de Janeiro: Zahar, 1986.

04. O culto do eu no templo da razão. In: Boletim do Museu Nacional (Três Ensaios sobre Pessoa e Modernidade). Rio de Janeiro, p. 1-27, agosto, 1993.

05. EHRENREICH, B.; ENGLISH, D. Witches, midwives, and nurses. New York, Feminist Press, 1973.

06. FOUCAULT, M. O nascimento do hospital. In: Microfísica do poder. Rio de Janeiro: Graal, 1979.

07.

Vigiar e punir: história da violência nas prisões. Petrópolis: Vozes, 1991.

08. GASTALDO, D.M.; MEYER, D.E. A formação da enfermeira: ênfase na conduta em detrimento do conhecimento. In: Rev. Bras. Enfermagem, Brasília, 42, jan/dez 1989.

09. GEERTZ, C. A interpretação das culturas. Rio de Janeiro: Zahar, 1978.

10. GUATTARI, F.; ROLNIK, S. Micropolítica: cartografias do desejo. Petrópolis: Vozes, 1986.

11. LOBO, E.S. Homem e mulher: imagens das ciências sociais. In: OLIVEIRA, E.M.de (org.). Mulheres: da domesticidade à cidadania. Águas de São Pedro, CNDM, 1987.
12. . O gênero da representação: movimento de mulheres e representação política no Brasil (1980-1990). In: Revista Brasileira de Ciências Sociais, n. 17: p. 07-14, out. 1991.

13. . O trabalho como linguagem: o gênero no trabalho. In: BIB, Rio de Janeiro, n. 31: pp. 07-16, jan/jul. 1991.

14. LOPES, M.J.M. O trabalho da enfermeira: nem público, nem privado, feminino, doméstico e desvalorizado. In: Revista Brasileira de Enfermagem, Brasília, n. 41: p. 211-217, jul/dez 1988.

15. NUNES, S.A. A medicina social e a questão feminina. In: PHYSIS - Revista de saúde coletiva, v.1, n.1, p. 49-76, 1991.

16. PENA, M.V.J. Mulheres e trabalhadoras: presença feminina na constituição do sistema fabril. Rio de Janeiro, Paz e Terra, 1981.

17. REZENDE, A.L.M. A imagem da enfermagem numa perspectiva formista. In: Enfermagem Revista, Belo Horizonte, v.1, n.1, p. 01-36, abr.1993.

18. WEBER, M. Ciência e política: duas vocações. São Paulo: Cultrix, 1993. 